\title{
PENGARUH PENERAPAN PRAKTIK TOTAL QUALITY MANAGEMENT (TQM) TERHADAP KINERJA KUALITAS (Studi Persepsi Karyawan Pada PT. Sermani Steel Makassar)
}

\author{
Musran Munizu \\ Jurusan Manajemen Fakultas Ekonomi Universitas Hasanuddin \\ Jl. Perintis Kemerdekaan KM. 10, Makassar 90245 \\ E-mail : m3.feunhas@yahoo.com; dan m3.feunhas@gmail.com \\ Hp. 081355137949
}

\begin{abstract}
The purpose of this research was to test and analyze the effect of TQM practices implementation which consists of leadership, strategic planning, customer focus, information and analysis, people management, and process management to quality performance at Sermani Steel in Makassar. The population were 300 employees and the sample were chosen 150 employees as respondents. Sample technique which used was simple random sampling. Method of analysis which use both descriptive statistic and Structural Equation Modelling (SEM). Data processing uses two statistic tools i.e : SPSS for windows and AMOS 4.01. The finding of research indicate that: TQM practices implementation which consists of leadership, strategic planning, customer focus, information and analysis, people management, and process management have significantly and positive effect on quality performance. Leadership has dominant effect on quality performance (Critical ratio $=7,860>$ t-table $=1,960$; and probability $=0,000<a=0,05$ )
\end{abstract}

Key words : Implementation of TQM Practices, Quality performance, Operation Management

Di Era Globalisasi sekarang ini setiap perusahaan atau industri dihadapkan pada perubahan lingkungan bisnis yang sangat cepat dan kompetitif. Mereka bersaing dalam menciptakan kondisi yang memungkinkan untuk dapat bersaing secara baik di pasar, baik di lingkup domestik maupun di pasar internasional. Agar dapat bersaing dan unggul, maka salah satu solusi yang harus dilakukan oleh perusahaan industri adalah mengadopsi dan menerapkan praktek pengelolaan operasi perusahaan yang terbaik. Hal ini akan membantu mereka dalam mengidentifikasi perubahan-perubahan dalam lingkungan yang dinamis dan merespon secara proaktif perubahan tersebut melalui perbaikan terus-menerus fungsi operasinya untuk mencapai kinerja superior. 
Satu hal yang sangat berarti dalam meningkatkan kinerja menghadapi tantangan persaingan tersebut adalah melalui perbaikan berkelanjutan pada aktivitas bisnis yang terfokus pada konsumen, meliputi keseluruhan organisasi dan penekanan pada fleksibilitas dan kualitas. Oleh karena itu, kualitas dan pengelolaannya dikaitkan dengan perbaikan berkelanjutan dilakukan oleh banyak perusahaan agar dapat mendorong peningkatan pasar dan memenangkan persaingan. Perusahaan yang tidak mengelola perubahan tersebut akan ketinggalan dan secara bertahap akan mengalami kemunduran.

Secara konseptual kualitas adalah totalitas bentuk dan karakteristik barang atau jasa yang menunjukkan kemampuannya untuk memuaskan kebutuhan yang tampak jelas maupun tersembunyi (Heizer dan Render, 2004). Beberapa pakar kualitas mendefinisikan kualitas dengan beragam interpretasi. Juran (1989), mendefinisikan kualitas secara sederhana sebagai 'kesesuaian untuk digunakan. Definisi ini mencakup keistimewaan produk yang memenuhi kebutuhan konsumen dan bebas dari defisiensi. Sedangkan Deming berpendapat kualitas adalah 'mempertemukan kebutuhan dan harapan konsumen secara berkelanjutan atas harga yang telah mereka bayarkan. Filosofi Deming membangun kualitas sebagai suatu sistem (Bhat dan Cozzolino, 1993)

Pengertian kualitas lebih luas oleh Bina Produktivitas Tenaga Kerja (1998) adalah : (1) Derajat yang sempurna (degree of exelence): mengandung pengertian komperatif terhadap tingkat produk (grade) tertentu; (2) Tingkat kualitas (quality level): mengandung pengertian kualitas untuk mengevaluasi teknikal; dan (3) Kesesuaian untuk digunakan (fitness for purpose user satisfaction), kemampuan produk atau jasa dalam memberikan kepuasan kepada pelanggan.

Heizer dan Render (2004) berpendapat bahwa kualitas terutama mempengaruhi perusahaan dalam empat hal, yaitu: 1) Biaya dan pangsa pasar: kualitas yang ditingkatkan dapat mengarah kepada peningkatan pangsa pasar dan penghematan biaya, keduanya juga dapat mempengaruhi profitabilitas; 2) Reputasi perusahaan: reputasi perusahaan mengikuti reputasi kualitas yang dihasilkan. Kualitas akan muncul bersamaan dengan persepsi mengenai produk baru perusahaan, praktek-praktek penanganan pegawai, dan hubungannya dengan pemasok; 3) Pertanggungjawaban produk: organisasi memiliki tanggung jawab yang 
besar atas segala akibat pemakaian barang maupun jasa; dan 4) Implikasi internasional: dalam era teknologi, kualitas merupakan perhatian operasional dan internasional. Agar perusahaan dan negara dapat bersaing secara efektif dalam perekonomian global, produknya harus memenuhi kualitas dan harga yang diinginkan. Dalam kenyataannya kualitas adalah konsep yang cukup sulit untuk dipahami dan disepakati. Dewasa ini kata kualitas mempunyai beragam interpretasi, tidak dapat didefinisikan secara tunggal, dan sangat tergantung pada konteksnya.

Salah satu bentuk praktik manajemen terbaik dalam perusahaan (best management practices) adalah Total Quality Management (TQM). Sejak awal tahun 1980-an TQM telah mendapat perhatian yang besar dari para manajer, karena terbukti mampu meningkatkan kinerja perusahaan. Total Quality Management (TQM) merupakan paradigma baru dalam menjalankan bisnis yang berupaya memaksimumkan daya saing organisasi melalui : fokus pada kepuasan konsumen, keterlibatan seluruh karyawan, dan perbaikan secara berkesinambungan atas kualitas produk, jasa, manusia, proses dan lingkungan organisasi (Krajewski et.al, 2003).

Menurut Sila et al., (2007) Total quality management (TQM) memainkan peranan yang sangat penting dalam meningkatkan kekuatan daya saing perusahaan. Di dalam pasar global yang berubah secara terus menerus, disamping pengiriman yang cepat (speed of delivery), kualitas produk juga menjadi salah satu elemen yang penting bagi perusahaan untuk dapat bersaing (competition). TQM merupakan pendekatan yang seharusnya dilakukan organisasi masa kini untuk memperbaiki kualitas produknya, menekan biaya produksi dan meningkatkan produktivitasnya. Implementasi TQM juga berdampak positif terhadap biaya produksi dan terhadap pendapatan (Gaspersz, 2005). Bukti lain juga menunjukkan bahwa perusahaan yang mengejar praktek terbaik TQM dapat mencapai keuntungan yang lebih tinggi dan cashflowsnya sebaik nilai pemegang saham yang lebih besar (Corbett dan Rastrick, 2000).

Pengukuran kinerja merupakan faktor penting bagi manajemen yang efektif. Secara umum, kinerja didefinisikan sebagai sejauh mana suatu operasi memenuhi tujuan kinerja, dan langkah-langkah utama dalam rangka memenuhi kebutuhan pelanggan. Fakta menunjukkan bahwa tanpa dilakukan suatu pengukuran terhadap 
kinerja, maka sulit untuk memperbaikinya. Oleh karena itu, meningkatkan kinerja organisasi memerlukan identifikasi terhadap variabel-variabel yang mempengaruhinya dan mengukurnya dengan akurat. Pengukuran kinerja operasional atau kinerja mutu sangat penting dilakukan bagi suatu organisasi, agar dapat tercapai efisiensi dan kinerja bisnis yang optimal (Demirbag et al., 2006).

Brah dan Lim (2006) mengatakan bahwa kinerja organisasi dapat diukur dalam dua dimensi kinerja yaitu kinerja operasional/kinerja mutu dan kinerja organisasi. Kinerja operasional mencerminkan kinerja operasi internal perusahaan dalam hal biaya dan pengurangan pemborosan, meningkatkan kualitas produk, pengembangan produk baru, memperbaiki kinerja pengiriman, dan peningkatan produktivitas. Indikator dan variabel tersebut dianggap sebagai faktor utama karena mereka mengikuti langsung dari tindakan yang diambil dalam kegiatan operasi perusahaan, sementara kinerja organisasi diukur dengan ukuran finansial seperti pertumbuhan pendapatan, laba bersih, rasio laba dengan pendapatan dan laba atas asset, dan nonukuran finansial seperti investasi dalam R\&D, dan kapasitas perusahaan untuk mengembangkan profil kompetitif.

Studi empiris yang menghubungkan antara TQM dan kinerja telah banyak dilakukan oleh para peneliti. Misalnya, Rahman (2001) melakukan studi pada 53 UKM Australia dan menemukan bahwa faktor-faktor kritis keberhasilan pelaksanaan TQM adalah kepemimpinan, strategi dan perencanaan, pemberdayaan karyawan dan keterlibatan karyawan, pelatihan dan pengembangan karyawan, informasi, dan analisis manajemen pelanggan.

Demirbag et al. (2006) melakukan studi empiris untuk mengidentifikasi faktorfaktor penting bagi keberhasilan TQM pada UKM di Turki. Mereka menyimpulkan bahwa ada tujuh CSF dari praktek TQM, yaitu data dan pelaporan kualitas, peran manajemen puncak, hubungan karyawan, manajemen kualitas pemasok, pelatihan, kebijakan mutu dan manajemen proses. Prayogo dan Hong (2008) melakukan penelitian pada 130 Industri Manufaktur unit R\&D di Korea. Mereka menemukan bahwa Implementasi TQM mempunyai pengaruh signifikan terhadap kinerja. Demikian pula studi yang dilakukan oleh Salaheldin (2009) yang menyimpulkan bahwa implementasi praktik TQM secara keseluruhan mempengaruhi kinerja perusahaan. Berdasarkan uraian tersebut di atas, maka tujuan yang hendak dicapai 
dalam penelitian ini adalah : "menguji dan menganalisis pengaruh praktek total quality management (TQM) terhadap kinerja kualitas pada PT. Sermani Steel Makassar".

\section{Model Kerangka Pikir dan Hipotesis}

Implementasi TQM dalam suatu organisasi saat ini sangat penting untuk mencapai keunggulan bersaing (competitive advantage). Peranan TQM disamping sebagai sebuah sistem manajemen kualitas, juga dapat meningkatkan kinerja mutu (quality performance) sebagai mediator dalam mencapai kinerja bisnis yang unggul. Tinggi rendahnya kinerja kualitas ditentukan oleh berhasil tidaknya suatu organisasi dalam menerapkan praktek TQM.

Berdasarkan uraian di atas, maka skema kerangka pikir penelitian ini disajikan sebagai berikut.

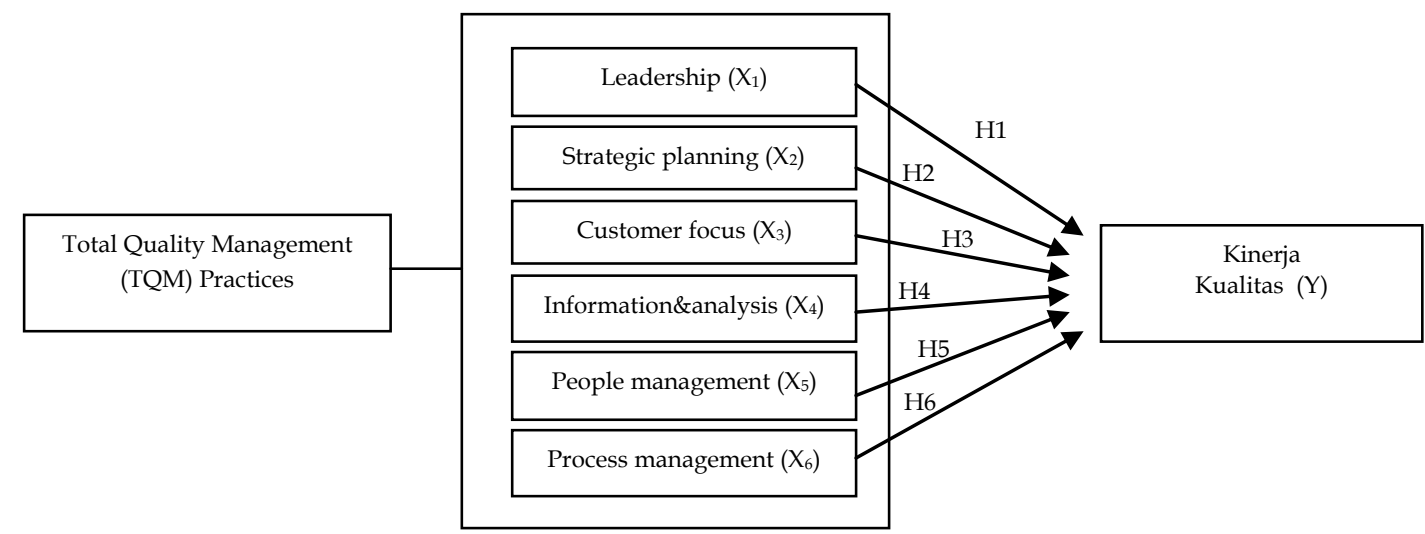

Gambar 1. Model Kerangka Pikir Penelitian

Berdasarkan kerangka pikir dan hasil-hasil penelitian yang telah diuraikan, maka dirumuskan hipotesis penelitian sebagai berikut : (1) Kepemimpinan (leadership) berpengaruh positif dan signifikan terhadap kinerja kualitas. (2) Perencanaan strategis (strategic planning) berpengaruh positif dan signifikan terhadap kinerja kualitas. (3) Fokus pada pelanggan (customer focus) berpengaruh positif dan signifikan terhadap kinerja kualitas. (4) Informasi dan analisis (information and analysis) berpengaruh positif dan signifikan terhadap kinerja kualitas. (5) Manajemen 
orang-orang (people management) berpengaruh positif dan signifikan terhadap kinerja kualitas. (6) Manajemen proses (process management) berpengaruh positif dan signifikan terhadap kinerja kualitas

\section{METODE}

Variable atau konstruk yang diuji hubungannya dalam penelitian ini, yaitu variable TQM yang terdiri atas Kepemimpinan (leadership) x1, Perencanaan strategis (strategic planning) x2, Fokus pada pelanggan (customer focus) x3, Informasi dan analisis (information and analysis) x4, Manajemen orang-orang (people management) x5, Manajemen proses (process management) x6 sebagai variabel exogen, dan Kinerja kualitas (y) sebagai variabel atau konstruk endogen.

Variabel atau konstruk TQM dalam penelitian ini mengadopsi model yang dikembangkan oleh Prayogo dan Brown (2004); dan Prayogo dan Dermott (2005). Sedangkan variabel kinerja kualitas diadopsi dari dari Australian and New Zealand manufacturers (AMC, 1994), dalam (Corbett dan Rastrick, 2000). Pengukuran persepsi karyawan terhadap indikator dan variable menggunakan Skala Likert dengan nilai $1-5$.

Populasi dalam penelitian ini adalah seluruh karyawan yang bekerja pada PT. Sermani Steel Makassar sejumlah 300 orang. Penentuan sampel menggunakan teknik acak sederhana (simple random sampling). Sugiyono (2008) dan Hair et.al (1998) berpendapat bahwa pada teknik sampel random sederhana, apabila subyek penelitian jumlahnya kurang dari 100, lebih baik diambil semua sehingga penelitiannya merupakan penelitian populasi. Selanjutnya jika jumlah subyeknya besar, dapat diambil antara $10-15 \%$, atau $20-25 \%$ atau lebih. Sehingga jumlah sampel ditetapkan sebanyak 50\% dari populasi atau 150 orang karyawan.

Pengujian validitas instrumen menggunakan korelasi product moment, di mana suatu item atau indikator dinyatakan valid apabila nilai korelasinya lebih dari 0,3 (Cooper dan Emory, 1999 dan Sugiyono, 2008). Kemudian pengujian reliabilitas instrumen menggunakan metode alpha cronbach, dimana suatu variable dinyatakan reliable apabila mempunyai nilai lebih dari 0,6. (Hair, et al. 1998; Augusty, 2002). Hasil pengujian validitas instrument menunjukkan bahwa keseluruhan 
indicator/item yang digunakan adalah valid $(\mathrm{r}>0,3)$. Kemudian hasil pengujian realibilitas instrument disajikan pada Tabel berikut.

Tabel 1. Hasil Pengujian Reliabilitas Instrumen

\begin{tabular}{|l|c|c|c|}
\hline \multicolumn{1}{|c|}{ Variabel/Konstruk } & $\begin{array}{c}\text { Jumlah } \\
\text { item/indikator }\end{array}$ & $\begin{array}{c}\text { Cronbach } \\
\text { Alpha }(\mathrm{a})\end{array}$ & Keterangan \\
\hline Kepemimpinan (leadership) x1 & 4 & 0,8552 & Reliabel \\
\hline Perencanaan strategis (strategic planning) x2 & 4 & 0,6254 & Reliabel \\
\hline Fokus pada pelanggan (customer focus) x3 & 5 & 0,7332 & Reliabel \\
\hline Informasi dan analisis (information and analysis) $\times 4$ & 4 & 0,6678 & Reliabel \\
\hline Manajemen orang-orang (people management) x5 & 5 & 0,6433 & Reliabel \\
\hline Manajemen proses (process management) x6 & 6 & 0,7555 & Reliabel \\
\hline Kinerja kualitas (quality performance) (y) & 6 & 0,7661 & Reliabel \\
\hline
\end{tabular}

Sumber : Data diolah

Berdasarkan tabel di atas dapat diketahui bahwa instrumen yang digunakan dalam pengumpulan data penelitian ini mempunyai tingkat reliabilitas yang tinggi. Hal ini dapat dilihat dari nilai alpha cronbach setiap variabel atau konstuk lebih besar dari nilai yang dipersyaratkan $(\alpha>0,60)$.

Ada 2 (dua) model dan teknik analisis data yang digunakan dalam mencapai tujuan penelitian ini, yaitu : (1) Analisis Statistik Deskriptif; dan (2) Structural Equation Modeling (SEM), yakni kumpulan teknik-teknik statistik yang memungkinkan pengujian sebuah rangkaian hubungan yang relatif rumit dan simultan. Pengolahan data menggunakan bantuan software Amos Versi 4.01, serta SPSS versi 17.00

Suatu model dikatakan fit (baik) dalam penggunaan analisis SEM, apabila memenuhi persyaratan-persyaratan sebagaimana disajikan pada tabel berikut.

Tabel 2. Goodness-Of-Fit Indices untuk evaluasi model

\begin{tabular}{|l|l|c|}
\hline \multicolumn{1}{|c|}{ Goodness of Fit Index } & \multicolumn{1}{|c|}{ Keterangan } & Cut-off Value \\
\hline $\mathrm{X}^{2}-$ Chisquare & $\begin{array}{l}\text { Menguji apakah covariance populasi yang } \\
\text { dietimasi sama dengan covarianve samle } \\
\text { (apakah model sesuai dengan data). Bersifat } \\
\text { sangat sensitive untuk sampel besar (diatas } \\
\text { 200) }\end{array}$ & Diharapkan kecil \\
\hline Probability & $\begin{array}{l}\text { Uji Signifikansi terhadap perbedaan matriks } \\
\text { covariance data dan matriks covariance } \\
\text { yang diestimasi }\end{array}$ & $\geq 0,05$ \\
\hline RMSEA & $\begin{array}{l}\text { Mengkompensasi kelemahan Chisquare } \\
\text { pada sampel besar }\end{array}$ & $\leq 0,08$ \\
\hline GFI & $\begin{array}{l}\text { Menghitung proporsi pertimbang variance } \\
\text { dalam matriks sampel yang dijelaskan oleh } \\
\text { matriks cavariance populasi yang }\end{array}$ & $\geq 0,90$ \\
\hline
\end{tabular}




\begin{tabular}{|l|l|c|}
\hline & $\begin{array}{l}\text { diestimasi (analog dengan } \mathrm{R}^{2} \text { dalam regresi } \\
\text { berganda) }\end{array}$ & \\
\hline AGFI & GFI yang disesuaikan terhadap DF & $\geq 0,90$ \\
\hline CMIND/DF & Kesesuaian antara data dan model & $\geq 0,95$ \\
\hline TLI & $\begin{array}{l}\text { Perbandingan antara model yang diuji } \\
\text { terhadap baseline model }\end{array}$ & $\geq 0,94$ \\
\hline CFI & $\begin{array}{l}\text { Uji kelayakan model yang tidak sensitive } \\
\text { terhadap besarnya sample dan kerumitan } \\
\text { model }\end{array}$ & \\
\hline
\end{tabular}

Sumber : (Hair et al., 1998; Augusty, 2002)

\section{HASIL}

Dari hasil analisis deskriptif diperoleh informasi bahwa responden penelitian ini dominan dengan jenis kelamin laki-laki, yakni sebesar 112 orang (74,7\%) dan perempuan 38 orang $(25,3 \%)$. Tingkat pendidikan responden dominan berada pada tingkat SMA yakni sebesar 90 orang (60\%), sisanya berada pada tingkat Sarjana/S1 sebanyak 20 orang (13,3\%), SMP masing-masing 14 orang (9,3\%) dan Diploma sebanyak 12 orang (8\%). Dilihat dari segi usia, responden penelitian ini dominan berada dalam kategori usia produktif, yaitu 31-40 tahun (41,3\%) dan 41-50 tahun (28\%), sisanya berada pada usia 20-30 tahun (18,7\%), dan usia 50-60 tahun (12\%).

Selanjutnya untuk menguji hipotesis dan menghasilkan suatu model yang fit, maka digunakan analisis Structural Equation Modelling (SEM). Dengan menggunakan bantuan perangkat lunak Amos 4.01 diperoleh hasil perhitungan goodness-of-fit indices (GFI) atas model lengkap yang menggambarkan jalinan sinergis antar masingmasing variabel penelitian sebagaimana disajikan pada Tabel berikut.

Tabel 3. Hasil Komputasi Kriteria Goodness-of-Fit Indices (GFI) Tahap Awal dan Tahap Akhir

\begin{tabular}{|l|c|c|c|c|}
\hline \multirow{2}{*}{\multicolumn{1}{c|}{ Kriteria }} & \multirow{2}{*}{ Nilai Cut-off } & \multicolumn{2}{c|}{$\begin{array}{c}\text { Hasil Komputasi } \\
\text { Model }\end{array}$} & $\begin{array}{c}\text { Keterangan } \\
\text { Model } \\
\text { Akhir }\end{array}$ \\
\cline { 3 - 4 } & Diharapkan kecil & 1750,662 & 69,255 & Baik \\
\hline Chi-square & $\geq 0,05$ & 0,000 & 0,240 & Baik \\
\hline Probabilitas signifikansi & $\geq 0,90$ & 0,866 & 0,944 & Baik \\
\hline GFI & $\leq 0,08$ & 0,090 & 0,001 & Baik \\
\hline RMSEA & $\geq 0,94$ & 0,829 & 0,962 & Baik \\
\hline TLI & $\geq 0,95$ & 0,830 & 0,988 & Baik \\
\hline CFI & & & & \\
\hline
\end{tabular}

Sumber : Data diolah 
Hasil perbandingan antara hasil perhitungan pada tahap awal dan tahap akhir dengan menggunakan kriteria goodness of fit suatu model sebagaimana disajikan pada tabel di atas menunjukkan kesesuaian. Setelah model di atas dinyatakan valid atau diterima maka analisis selanjutnya adalah dengan melihat nilai loading factor serta probabilitas dari masing-masing variabel yang digunakan. Secara lengkap sebagaimana disajikan dalam tabel berikut.

Tabel 4. Loading Factor, Critical Ratio (CR), dan Probabilita(P) Hubungan antar Variabel

\begin{tabular}{|c|c|c|c|c|}
\hline Variabel/Konstruk & $\begin{array}{l}\text { Loading } \\
\text { Factor }\end{array}$ & C.R. & $\mathrm{P}$ & Keterangan \\
\hline Kinerja Kualitas Ł---- Kepemimpinan & 0,664 & 7,860 & 0,000 & Signifikan \\
\hline Kinerja Kualitas Ł---- Perencanaan strategis & 0,514 & 6,600 & 0,001 & Signifikan \\
\hline Kinerja Kualitas Ł---- Fokus pada pelanggan & 0,490 & 5,245 & 0,003 & Signifikan \\
\hline Kinerja Kualitas Ł---- Informasi dan analisis & 0,198 & 2,162 & 0,042 & Signifikan \\
\hline $\begin{array}{l}\text { Kinerja Kualitas } \leftarrow---- \text { Manajemen orang- } \\
\text { orang }\end{array}$ & 0,264 & 3,774 & 0,026 & Signifikan \\
\hline Kinerja Kualitas Ł---- Manajemen proses & 0,488 & 5,188 & 0,005 & Signifikan \\
\hline
\end{tabular}

Sumber : Data diolah

Pada tabel diatas, terlihat bahwa dari berbagai hubungan yang terjadi antar variabel, nampaknya semua memiliki hubungan yang signifikan, karena memiliki nilai $\mathrm{P}$ (probabilitas) $\leq 0,05$ dan Critical Ratio $(\mathrm{CR}) \geq 1,96$. Variabel yang memiliki pengaruh yang signifikan dan positif $(\mathrm{P} \leq 0,05)$, adalah : (1) kepemimpinan terhadap kinerja kualitas $(0,000)$; (2) perencanaan strategis terhadap kinerja kualitas $(0,001)$; $(3)$ fokus pada pelanggan terhadap kinerja kualitas (0,003); (4) Informasi dan analisis terhadap kinerja kualitas $(0,042)$; (5) manajemen orang-orang terhadap kinerja kualitas (0,026); dan (6) manajemen proses terhadap kinerja kualitas $(0,005)$. Variabel atau kontruk yang mempunyai pengaruh yang dominan adalah kepemimpinan terhadap kinerja kualitas dengan nilai loading factor sebesar 0,664 dan propabilita sebesar 0,000 .

Adapun model lengkap yang dapat menjelaskan hubungan yang terjalin di antara variabel disajikan sebagai berikut :

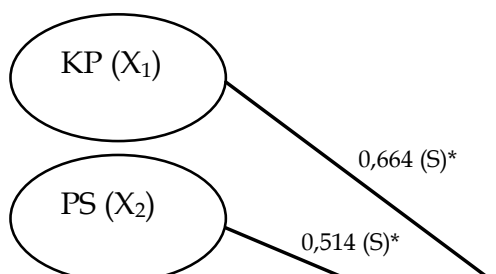


Gambar 2. Hasil pengujian hubungan antara praktik TQM (Kepemimpinan, Perencanaan strategis, Fokus pada pelanggan, Informasi dan analisis, Manajemen orang-orang, Manajemen proses) dengan Kinerja Kualitas.

Keterangan : *) Hubungan dan Pengaruh antar variabel signifikan

$\mathrm{KP}=$ Kepemimpinan (leadership)

$\mathrm{PS}=$ Perencanaan strategis (strategic planning)

$\mathrm{FP}=$ Fokus pada pelanggan (customer focus)

IA = Informasi dan analisis (information and analysis)

$\mathrm{MO}=$ Manajemen orang-orang (people management)

$\mathrm{MP}=$ Manajemen proses (process management)

$\mathrm{KK}=$ Kinerja kualitas (quality performance)

\section{PEMBAHASAN}

Berdasarkan nilai critical ratio dan probabilitas yang disajikan pada tabel di atas, nampak bahwa variabel kepemimpinan mempunyai pengaruh yang positif dan signifikan terhadap kinerja kualitas. Dimana nilai CR (critical ratio) lebih besar daripada nilai yang disyaratkan sebesar 1,960 $(7,860>1,960)$, serta nilai probabilitas lebih kecil daripada $\alpha=0,05(0,000<0,05)$. Oleh karena itu, Hipotesis I yang diajukan dalam penelitian ini terbukti atau didukung oleh fakta empiris.

Nilai loading factor juga menunjukkan bahwa variabel kepemimpinan mempunyai pengaruh yang kuat dan positif terhadap kinerja kualitas dengan kontribusi sebesar 0,664 atau $66,4 \%$. Hasil penelitian ini mendukung pendapat 
bahwa komitmen dan dukungan manajemen merupakan salah satu elemen kunci keberhasilan implementasi TQM (Rahman, 2001; Munizu, 2002; Demirbag, et.al, 2006). Komitmen manajemen juga mempunyai pengaruh signifikan terhadap kinerja mutu dan kinerja organisasi (Prayogo dan Brown, 2004; Prayogo dan Dermott, 2005).

Komitmen manajemen dalam mendukung suksesnya implementasi TQM guna mencapai kinerja yang tinggi dalam kualitas produknya dapat diwujudkan melalui suatu sistem manajemen yang terpadu dari tingkat pimpinan puncak sampai karyawan yang paling bawah. Sehingga perusahaan memperoleh kemajuan secara konsisten dalam mencapai standar kinerja mutu yang telah ditetapkan bersama secara bertahap dan terukur.

Berdasarkan nilai critical ratio dan probabilitas yang disajikan pada tabel di atas, nampak bahwa variabel perencanaan strategis mempunyai pengaruh yang positif dan signifikan terhadap kinerja kualitas. Dimana nilai CR (critical ratio) lebih besar daripada nilai yang disyaratkan sebesar $1,960(6,600>1,960)$, serta nilai probabilitas lebih kecil daripada $\alpha=0,05(0,001<0,05)$. Oleh karena itu, Hipotesis II yang diajukan dalam penelitian ini terbukti atau didukung oleh fakta empiris.

Nilai loading factor juga menunjukkan bahwa variabel perencanaan strategis mempunyai pengaruh yang cukup kuat dan positif terhadap kinerja kualitas dengan kontribusi sebesar 0,514 atau 51,4\%. Hasil penelitian ini mendukung pendapat Heizer dan Render (2004); dan Krajewski et.al, (2003) bahwa perencanaan strategis dalam organisasi mutlak diperlukan sebagai dasar acuan dalam pengendalian program perbaikan mutu. Dengan adanya perencanaan yang baik dalam organisasi, maka program-program yang berkaitan dengan peningkatan mutu produk akan lebih terarah dan terukur, sehingga kinerja kualitas dapat ditingkatkan secara terus menerus (continous improvement)

Berdasarkan nilai critical ratio dan probabilitas yang disajikan pada tabel di atas, nampak bahwa variabel fokus pada pelanggan mempunyai pengaruh yang positif dan signifikan terhadap kinerja kualitas. Dimana nilai CR (critical ratio) lebih besar daripada nilai yang disyaratkan sebesar 1,960 $(5,245>1,960)$, serta nilai probabilitas lebih kecil daripada $\alpha=0,05(0,003<0,05)$. Oleh karena itu, Hipotesis III yang diajukan dalam penelitian ini terbukti atau didukung oleh fakta empiris. 
Nilai loading factor juga menunjukkan bahwa variabel fokus pada pelanggan mempunyai pengaruh yang cukup kuat dan positif terhadap kinerja kualitas dengan kontribusi sebesar 0,490 atau 49\%. Hasil penelitian ini mendukung pendapat bahwa fokus pada konsumen merupakan salah satu elemen kunci keberhasilan implementasi TQM (Krajewski et.al, 2003; Corbett dan Rastrick, 2000; Prayogo dan Brown, 2004; dan Prayogo dan Dermott, 2005).

Fokus pada konsumen merupakan salah satu faktor mikro dari dalam perusahaan yang mempengaruhi perubahan dan pengembangan kinerja suatu organisasi, juga sebagai salah satu variabel yang secara signifikan mempengaruhi kinerja kualitas dan kinerja bisnis (Demirbag et.al, 2006; Brah dan Lim, 2006).

Berdasarkan nilai critical ratio dan probabilitas yang disajikan pada tabel di atas, nampak bahwa variabel informasi dan analisis mempunyai pengaruh yang positif dan signifikan terhadap kinerja kualitas. Dimana nilai CR (critical ratio) lebih besar daripada nilai yang disyaratkan sebesar 1,960 $(2,162>1,960)$, serta nilai probabilitas lebih kecil daripada $\alpha=0,05(0,042<0,05)$. Oleh karena itu, Hipotesis IV yang diajukan dalam penelitian ini terbukti atau didukung oleh fakta empiris.

Nilai loading factor juga menunjukkan bahwa variabel informasi dan analisis mempunyai pengaruh yang positif terhadap kinerja kualitas dengan kontribusi sebesar 0,198 atau 19,8\%. Hasil penelitian tersebut mendukung pendapat pakar kualitas, bahwa informasi dan analisis dengan bantuan piranti (tools) statistik merupakan salah satu elemen kunci keberhasilan implementasi TQM. (Krajewski et.al, 2003; Corbett dan Rastrick, 2000; dan Prayogo dan Dermott, 2005).

Menurut Brah dan Lim (2006) penggunaan piranti statistik sangat berarti dalam membantu proses perbaikan berkelanjutan, karyawan memanfaatkan piranti statistik sebagai bentuk keterlibatan dan kontribusinya, menjadikan kesadaran karyawan terhadap kualitas meningkat, dan prilaku dan sikap karyawanpun berubah. Beberapa piranti statistik yang banyak digunakan oleh perusahaan dalam mengendalikan dan memperbaiki aktivitas perusahaan yang berkaitan dengan semua aspek kualitas diantaranya adalah: sumbang saran (brainstorming), checklists, diagram pareto, diagram tulang ikan (fishbone diagram), flow chart, control chart, scatter diagram, dan histogram. 
Berdasarkan nilai critical ratio dan probabilitas yang disajikan pada tabel di atas, nampak bahwa variabel manajemen orang-orang mempunyai pengaruh yang positif dan signifikan terhadap kinerja kualitas. Dimana nilai CR (critical ratio) lebih besar daripada nilai yang disyaratkan sebesar $1,960(3,774>1,960)$, serta nilai probabilitas lebih kecil daripada $\alpha=0,05(0,026<0,05)$. Oleh karena itu, Hipotesis $V$ yang diajukan dalam penelitian ini terbukti atau didukung oleh fakta empiris.

Nilai loading factor juga menunjukkan bahwa variabel manajemen orang-orang mempunyai pengaruh yang positif terhadap kinerja kualitas dengan kontribusi sebesar 0,264 atau $26,4 \%$. Hasil penelitian ini sejalan dengan pendapat bahwa pemberdayaan dan keterlibatan karyawan merupakan salah satu elemen kunci keberhasilan implementasi TQM (Krajewski et.al, 2003; Corbett dan Rastrick, 2000; Munizu, 2002; dan Prayogo dan Brown, 2004). Beberapa bentuk upaya pemberdayaan karyawan oleh perusahaan, diantaranya adalah: dibentuknya kelompok kerja (Small Group Activity) atau Gugus Kendali Mutu (GKM), pertemuan berkala, aktivitas sumbang saran (brain storming), pengakuan dan penghargaan atas prestasi karyawan di bidang perbaikan dan peningkatan kualitas. Pemberdayaan dan pengakuan atas eksistensi karyawan oleh perusahan tersebut terbukti telah efektif membangun budaya dan kinerja kualitas

Berdasarkan nilai critical ratio dan probabilitas yang disajikan pada tabel di atas, nampak bahwa variabel manajemen proses mempunyai pengaruh yang positif dan signifikan terhadap kinerja kualitas. Dimana nilai CR (critical ratio) lebih besar daripada nilai yang disyaratkan sebesar 1,960 $(5,188>1,960)$, serta nilai probabilitas lebih kecil daripada $\alpha=0,05(0,005<0,05)$. Oleh karena itu, Hipotesis VI yang diajukan dalam penelitian ini terbukti atau didukung oleh fakta empiris.

Nilai loading factor juga menunjukkan bahwa variabel manajemen proses mempunyai pengaruh yang cukup kuat dan positif terhadap kinerja kualitas dengan kontribusi sebesar 0,488 atau 48,8\%. Hasil penelitian ini mendukung pendapat Krajewski et.al, (2003); Corbett dan Rastrick, (2000); Prayogo dan Brown, (2004); dan Salaheldin (2009) yang mengatakan bahwa manajemen proses merupakan salah satu elemen TQM yang mempengaruhi kinerja kualitas dan kinerja bisnis.

\section{KESIMPULAN DAN SARAN}




\section{Kesimpulan}

Berdasarkan hasil penelitian dan pembahasan dapat disimpulkan bahwa variabel praktik TQM yang terdiri atas (1) Kepemimpinan; (2) Perencanaan strategis; (3) Fokus pada pelanggan; (4) Informasi dan analisis; (5) Manajemen orang-orang; dan (6) Manajemen proses mempunyai pengaruh positif dan signifikan terhadap kinerja kualitas. Hal ini mengindikasikan bahwa derajat meningkat atau menurunnya kinerja mutu produk sangat ditentukan oleh variabel-variabel TQM tersebut. Komitmen manajemen yang kuat dan konsisten terhadap implementasi TQM dalam organisasi perusahaan sangat dominan dalam menentukan kinerja kualitas produk. Program-program peningkatan kualitas yang telah direncanakan dalam kerangka TQM akan berjalan dengan baik apabila mendapatkan dukungan penuh dari pihak pimpinan/manajemen perusahaan.

\section{Saran}

Pihak manajemen perusahaan hendaknya memperhatikan variabel-variabel TQM yang berpengaruh signifikan terhadap peningkatan kinerja kualitas seperti; komitmen manajemen, perencanaan strategis, fokus pada pelanggan, dan manajemen proses dalam rangka mencapai kinerja dan daya saing perusahaan yang berkelanjutan (sustainability competitive advantage). Variabel informasi dan analisis, dan manajemen orang-orang/pemberdayaan karyawan harus lebih mendapatkan perhatian, karena implementasinya dalam perusahaan belum optimal. Penggunaan peralatan statistic $(\mathrm{SQC}=$ statistical quality control), pemberian pelatihan mutu pada karyawan, pembuatan task force, GKM (gugus kendali mutu), dan instrument mutu lainnya harus dioptimalkan pemanfaatannya agar memberikan hasil yang lebih baik dalam mendukung tercapainya kinerja kualitas produk yang superior. Penelitian ini masih menunjukkan banyak kelemahan, karena itu bagi peneliti-peneliti selanjutnya dapat mengembangkan penelitian ini dengan menambah jumlah unit organisasi, jumlah variable yang akan diteliti, dan aplikasinya pada sector lainnya seperti sector jasa.

\section{DAFTAR PUSTAKA}


Bhat, V. and J. Cozzolino. 1993. Total Quality: An Effective Management Tool, Quality Management Journal. hal.101-123.

Bina Produktivitas Tenaga Kerja. 1998. Manajemen Mutu Terpadu. Departemen Tenaga Kerja. Jakarta.

Brah, S. and Lim, H. 2006. "The effects of technology and TQM on the performance of logistics companies", International Journal of Physical Distribution $\mathcal{E}$ Logistics Management, Vol. 36 No. 3, hal. 192-209.

Cooper, Donald R. Dan C.William Emory. 1999. Business Research Methods, Fifth Edition, Richard D. Irwin Inc. Chicago.

Demirbag, M., Tatoglu, E., Tekinkus, M. and Zaim, S. 2006. "An analysis of the relationship between TQM implementation and organizational performance: evidence from Turkish SMEs", Journal of Manufacturing Technology Management, Vol. 17 No. 6, hal. 829-47.

Gaspersz, V. 2005. Total Quality Management. Jakarta : PT. Gramedia Pustaka Umum.

Hair Jr., Yoseph F., Rolph E. Anderson, Ronald L. Papham, William Black. 1998. Multivariate Data Analysis, $5^{\text {th }}$ edition, Prentice-Hall, Inc., New Jersey

Juran, J.M. 1989. Juran on Leadership for Quality, The Free Press, MacMillan,Inc. E. Nugroho (penterjemah). Kepemimpinan Mutu. Jakarta: Pustaka Binaman Pressindo.

Krajewski, J. Lee and P. R. Larry. 2003. Operations Management Strategy and Analysis, Fifth Edition, Addison-Wesley Publising Company Inc.

Lawrence M. Corbett and Kate N. Rastrick. 2000. Quality performance and organizational culture : A New Zealand study, International Journal of Quality $\mathcal{E}$ Reliability Management, Vol. 17 No. 1, hal. 14-26.

Munizu, M. 2002. Analisis Persepsi Karyawan atas Keberhasilan Pelaksanaan Gugus Kendali Mutu (GKM) pada Karyawan Produksi Pabrik Karung (PK) Rosella Baru, PTPN XI (Persero) Surabaya. Tesis. Program Pasca Sarjana, Unair, Surabaya.

Prajogo, Daniel.I., and Brown, A. 2004. "The Relationship Between TQM Practice and Quality Performance and the Role of Formal TQM Programs: An Australian Empirical Study". Quality Management Journal. 11(4):hal. 31-42.

Prajogo, Daniel I., and Christopher M. McDermott. 2005. The relationship between total quality Management practices and organizational culture, International Journal of Operations \& Production Management Vol. 25 No. 11, hal. 1101-1122. 
Prajogo, Daniel I. and Soon W. Hong. 2008. The effect of TQM on performance in RED environments: A perspective from South Korean firms, Technovation 28 : hal. 855863.

Rahman, S.. 2001. "A comparative study of TQM practice and organisational performance of SMEs with and without ISO 9000 certification", International Journal of Quality \& Reliability Journal, Vol. 18 No. 1, hal. 35-49.

Render, Barry and Jay Heizer. 2004, Operations Management, International Edition, Pearson Education Inc. Upper Saddle River, New Jersey.

Salaheldin, Ismail. 2009. Critical success factors for TQM implementation and their impact on performance of SMEs, International Journal of Productivity and Performance Management Vol. 58, No. 3, hal. 215-235

Sila, I. 2007. "Examining the effects of contextual faktors on TQM and performance through the lens of organizational theory: an empirical study", Journal of Operations Management,Vol. 25 No. 1, hal. 83-109.

Sugiyono. 2008. Statistik Untuk Penelitian. Bandung: CV. Alfabeta. 